This is also architecture: architectural superimposable as a manifestation of agonism in the city

PALABRAS CLAVE | SOBREPUESTO | AGENCIA | AGONISMO | HABITANTE | PODER

KEYWORDS | SUPERIMPOSABLE | AGENCY | AGONISM | INHABITANT | POWER
| RESUMEN |

La arquitectura y la ciudad son generalmente consideradas como obra exclusiva de nuestra disciplina y profesión. Esta idea no es del todo correcta, pues existe una arquitectura que nace desde lo cotidiano y lo ordinario, un mundo que como arquitectos hemos rechazado e ignorado a lo largo del tiempo. Este artículo plantea que la arquitectura es un agente activo en lo social y político, generando conflictos y reacciones en sus habitantes, quienes dan paso a un proceso de domesticación de su entorno mediante los sobrepuestos arquitectónicos. Entendemos estos objetos como parte de nuestro campo de estudio y herramientas útiles para comprender dinámicas sociales, tales como los conflictos de poder.

\section{| ABSTRACT |}

Architecture and the city are generally considered an exclusive work of our discipline and profession. This idea is not entirely correct because there is an architecture that arises from the everyday and the ordinary, a world that as architects we have rejected and ignored over time. This article proposes that architecture is an active agent in the social and political sphere that generates conflicts and and political sphere that generates conflicts and
reactions in its inhabitants who give way to a process of domestication of their environment through the architectural superimposable. We understand these objects as part of our field of study and useful tools for the understanding of social dynamics such as conflicts of power.

\title{
Esto también es arquitectura. Sobrepuestos arquitectónicos como manifestaciones agonistas en la ciudad*
}

\author{
SEBASTIÁN SIMONETTI GREZ** · Samtiago, Chile · ssgrez1992@gmail.com
}

\section{INTRODUCCIÓN}

Plantear que la bandera soviética alzada sobre el Reichstag en 1945 es arquitectura podría generar más de alguna discrepancia. También podría generarla afirmar que la bandera gigante por la educación, desplegada por estudiantes chilenos dentro de un centro comercial en 2012 sea parte de nuestra disciplina. Entender las banderas $u$ objetos comunes como ajenos a nuestros límites disciplinarios forma parte de una visión tradicional que aún enmarca a la arquitectura y la ciudad como resultados de un autor o un genio constructor, personificado en el arquitecto. Excluir objetos comunes de nuestro campo de estudio por no poder digerirlos, entenderlos ni aceptarlos (Walker, 2010) es también entender a la Arquitectura solo como se presenta en los fundamentals de Rem Koolhaas en la pasada Bienal de Venecia de 2014: piso, muro, cielo, tejado, puerta, ventana, fachada, rampa, balcón, pasillo, chimenea, baño, escalera, escala mecánica y ascensor (Koolhaas, 2014).

Según Koolhaas estos son los elementos inevitables de toda arquitectura utilizada por cualquier arquitecto, en cualquier lugar y momento (Koolhaas, 2013). En este contexto pareciera no haber espacio para las mencionadas banderas ni para otros objetos ordinarios que aparecen y transforman la arquitectura con el tiempo y uso. Por el contrario, esta visión considera la arquitectura como un objeto pasivo y apolítico, que no participa en los procesos sociales y políticos. La arquitectura vista de esta manera es planteada como una construcción de autores únicos, como obras finalizadas, renders eternos que no se someten al paso del tiempo, tal como sería el Pabellón de Barcelona según Andrés Jaque (Jaque, 2013).

Sin embargo, la arquitectura no debe considerarse como una construcción única del arquitecto, sino que también como el resultado de una transformación y domesticación colectiva por parte de sus habitantes. Entendemos entonces a la arquitectura no como un elemento terminado y pasivo tras su construcción sino que como un actor que genera respuestas y acciones en sus habitantes, quienes continúan su transformación cargándola de un significado doméstico y apartándola de su estado de render o únicamente compuesta por fundamentals. La domesticación arquitectónica es aquel proceso

* Artículo en base a los resultados del seminario de investigación "Santiago como escenario de confrontaciones agenciadas: manifestaciones agonistas a través del sobrepuesto arquitectónico" realizado por el autor durante el semestre de otoño de 2015 en la Facultad de Arquitectura y Urbanismo de la Universidad de Chile. Profesor guía: Mario Marchant Lannefranque.

** Licenciado en Arquitectura (2014) por la Facultad de Arquitectura y Urbanismo de la Universidad de Chile. 
1. El dialecto como la transformación de lo formal, según las tradiciones locales. Elaboración propia.

en que el habitante otorga identidad propia, en un lugar doméstico, cercano a una domus (casa) cargado de significado. Los límites formales de la arquitectura pasan a estar en otro plano, tras ser adaptadas y apropiadas por el habitante, dando paso a la aparición de un nuevo elemento (¿̇un elemento fundamental olvidado?) que la lleva desde su estado genérico a uno particular. Este elemento es la manifestación una domesticación arquitectónica, al cual denominamos sobrepuesto arquitectónico.

\section{SOBREPUESTOS ARQUITECTÓNICOS}

Parecería difícil definir los sobrepuestos arquitectónicos. Por ello tomaremos como ejemplo la lengua castellana, una de las más habladas del mundo. Nuestro idioma posee sus propias reglas y órdenes por las cuales todo quien que lo hable se debe guiar. Esta es la parte formal del castellano. Sin embargo, al estudiarlo en cada parte en la que se habla, más allá de los límites políticos de los países, entrando en rincones y localidades hispanoparlantes, veremos cómo esta lengua muta (Figura 1). Según el lugar donde se hable y según las condiciones locales, como el contexto histórico, natural o social, el castellano se complejiza con elementos únicos sobrepuestos, un sistema de signos que se entiende dentro de esa localidad, pero con dificultad fuera de ella. En términos formales, aparece el dialecto (Alvar, 1996).

Comparar la arquitectura con el lenguaje podría resultar erróneo dado que, técnicamente, la formalidad de la arquitectura no posee una gramática estructurada y reglas como un idioma. No obstante teniendo en cuenta esas evidencias, postulamos que la arquitectura, sea o no con intención del arquitecto, actúa como un sistema comunicacional. La arquitectura, más allá de sus fundamentals es un estímulo permanente que genera respuestas (Jecks, 1977). Esta capacidad de estimulación de la arquitectura, desde su origen al ser construida hasta su proceso final de domesticación nos permite sostener que funciona como un lenguaje, un

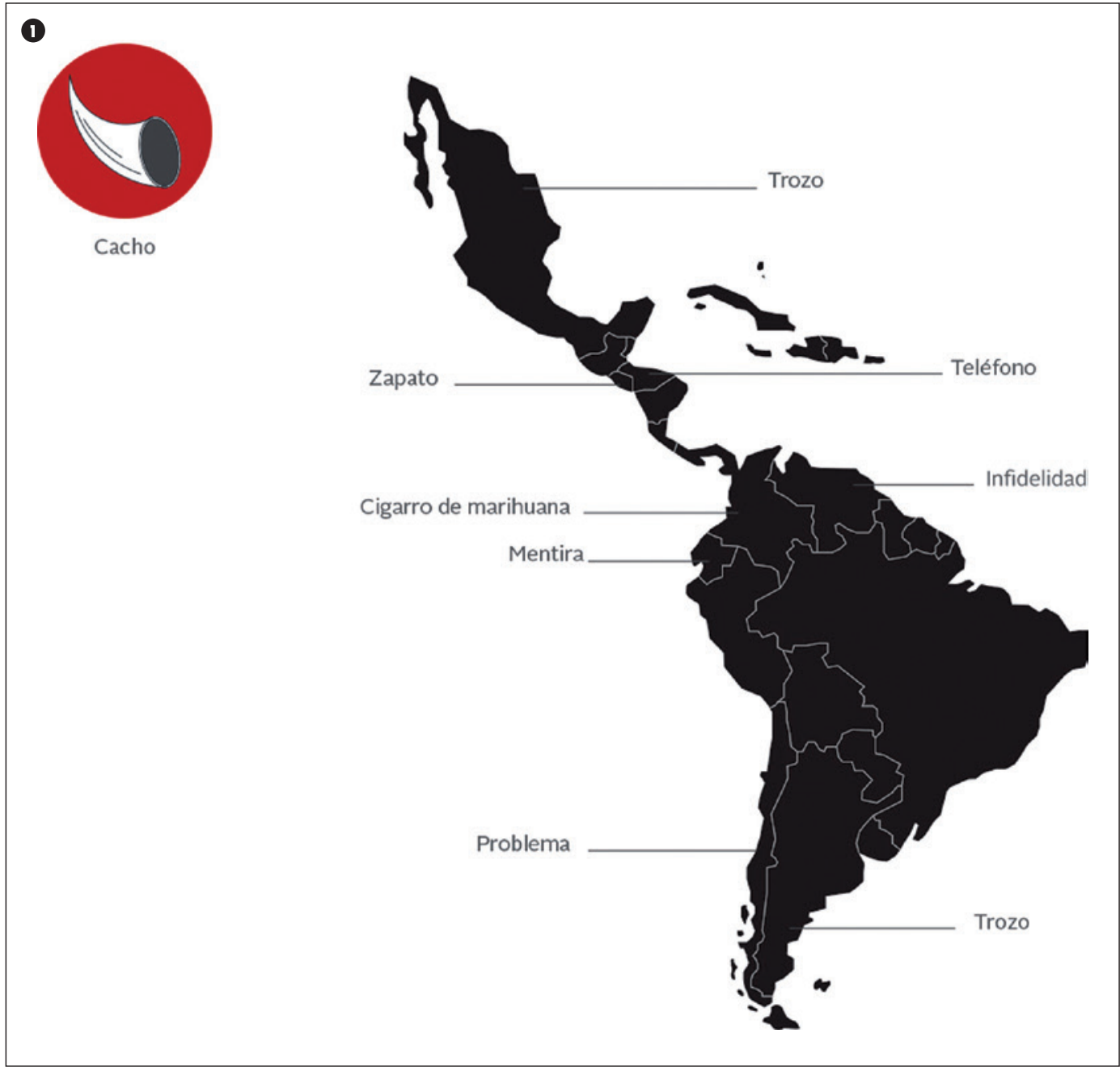

elemento comunicativo que actúa como emisor de mensajes y provocador de respuestas en el habitante. Los sobrepuestos arquitectónicos serían entonces el dialecto de la arquitectura, una estructura informal intervenida por el colectivo sobre una base formal.

Podemos definir los sobrepuestos arquitectónicos como un conjunto de elementos, generalmente objetos, que complejizan y cambian el espacio formal de la arquitectura o el espacio público, a partir de la estructura, forma y función original de estos, otorgándole una carga simbólica diferente y significativa para el o los habitantes. El sobrepuesto se constituye como una nueva capa de comunicación arquitectónica. Los sobrepuestos no son cualquier objeto dispuesto sobre la arquitectura, sino que pueden distinguirse en cuatro niveles que van desde lo íntimo a lo público, con sus objetivos y destinatarios particulares.

\section{SOBREPUESTOS ÍNTIMOS}

Aparecen en los espacios más íntimos y personales del habitar en la arquitectura, tales como habitaciones o espacios personales de trabajo. No existen regulaciones para el ámbito íntimo más que las conductas morales e 
ideológicas que pueda traer consigo el mismo habitante, lo que lo convierte en el sobrepuesto de mayor libertad expresiva. Son elementos que transforman la arquitectura en una extensión del habitante al incluir su historia y personalidad. Así, los sobrepuestos íntimos comunes que podríamos encontrar serían cuadros, pinturas, libros, fotografías, recuerdos u objetos de significancia personal, los cuales toman una relevancia dentro del espacio arquitectónico y conllevan una estrategia en su disposición espacial. En este sentido, los sobrepuestos íntimos tienen como fin la transmisión de significados personales, los cuales son propios del habitante y que para un tercero podrían no tener relevancia alguna.

\section{SOBREPUESTOS PRIVADOS}

Entendemos lo privado como el espacio donde el habitante se desenvuelve diariamente, reconoce como propio pero donde no manifiesta la extensión de lo íntimo al compartirse con otros. Aquí es donde aparecen los primeros conflictos y negociaciones del espacio con el fin último de domesticarlo. Los habitantes se reconocen como válidos propietarios de un mismo espacio y por lo mismo crean normas de convivencia en donde el resultado de la negociación es la aparición de los sobrepuestos que se pueden manifestar como fotografías comunes, libros, cuadros u ornamentación. Si se realizara un estudio de todas las salas de estar de una torre de departamentos, a pesar de ser todos los espacios arquitectónicamente iguales, ninguno sería igual al otro.

\section{SOBREPUESTOS SEMIPÚBLICOS}

Aquí es donde interactúan los sujetos sociales que no tienen ni la proximidad de aquellos que comparten espacios privados pero tampoco la suficiente distancia de un espacio público. Son los espacios intermedios, como pasillos, escaleras, patios comunes, ascensores, quinchos o recepciones. Aquí la domesticación se desarrolla de menor manera y por lo mismo la manifestación de sobrepuestos arquitectónicos es escasa, como podrían ser los felpudos. Actúan como un nexo del espacio interior con el poco doméstico y ajeno espacio exterior, comunicando en una primera instancia aquello que se encuentra dentro.

\section{SOBREPUESTOS PÚBLICOS}

Es el espacio en teoría transparente, en contraposición a lo opaco del mundo íntimo, en donde los habitantes se ven enfrentados a una cantidad considerable de estímulos que podrían provocar en ellos acciones en respuesta. El espacio público es aquel donde los individuos generalmente no tienen mayor relación que pertenecer a una misma ciudad o sociedad y, por lo tanto, las acciones comunicativas dejan de ser personales y apuntan ahora a mensajes relacionados con las actividades sociales que involucran a las masas y no a los individuos como tal. Los sobrepuestos públicos pueden o no ser compartidos ideológicamente, generando el disenso y conflicto urbano.

Los sobrepuestos públicos son de distinto tipo, incluyendo artísticos (murales, graffitis, stencils o pinturas), económicos (publicidad, carteles comerciales, luces de neón, afiches) o políticos (propaganda, afiches, intervenciones urbanas). Esta última categoría resulta interesante, pues a través de estos sobrepuestos la arquitectura se transforma en lo que Jaque (2014) definiría como dispositivos políticos en que desde el espacio privado, como un edificio, se genera una red con lo público y lo común.

Estos sobrepuestos buscan convencer o exponer a los habitantes una postura política particular frente a un tema polémico o de debate, provocando el conflicto y disenso en el espacio público. Es por ello que la política en el espacio público es el lugar de confrontación de ideas que buscan la preservación de los ideales colectivos y también personales de los habitantes. Así, los sobrepuestos políticos tienen una gran carga simbólica dentro de la acción comunicativa en la ciudad y la arquitectura.

\section{ARQUITECTURA, SOBREPUESTOS Y AGONISMO}

Los sobrepuestos arquitectónicos son la expresión física de la domesticación y transformación que realizan los habitantes de un entorno construido para cargarlo con un significado nuevo. Esto le otorga a la ciudad y a la arquitectura ya no una condición estática, pasiva y apolítica sino que por el contrario, le otorga un rol activo dentro de las relaciones sociales y políticas que transforman lo social. Esta propuesta se relaciona con la Teoría del Actor-Red de Bruno Latour, la cual plantea un giro hacia una "sociología de las asociaciones" donde solo existen "formaciones de grupos" conformados ya no solo por humanos, sino que también por objetos que poseen la misma capacidad o potencial de inducir acciones. Lo material posee un rol activo y no de mero intermediario, es decir, se transforma en un actor o actante, que según Latour es cualquier elemento que modifique el estado de otro a través de su incidencia (Latour, 2005). Esa potencialidad de incidir o "hacer que otro haga algo" se le llama agencia. Tal es el punto de importancia que se le da a los objetos, que el entretejido de las fuerzas no-humanas con lo humano cambia el mismo concepto de sociedad a colectivo

Es esta agencia que posee la arquitectura la que le vuelve un actor políticamente activo dentro de la sociedad, creando disenso y conflictos políticos agonistas. Según la politóloga Chantal Mouffe, el agonismo establece una relación domesticada del conflicto, donde si bien se entiende que no hay una solución racional al conflicto entre las partes, estas reconocen su legitimidad como oponentes y la pertenencia a un mismo espacio político común donde se desarrolla el conflicto (Mouffe, 2007).

En el caso de la arquitectura y la ciudad, el conflicto no queda al margen, pues es en sus espacios y usando sus formas como soporte, desde donde se envían los mensajes conflictivos que impulsan el desarrollo crítico de las sociedades. Ello se observa a lo largo 
2. Bandera soviética sobre el Reichstag nazi. Fuente: elaboración propia a partir de la fotografía original de Yevgueni Jaldéi.

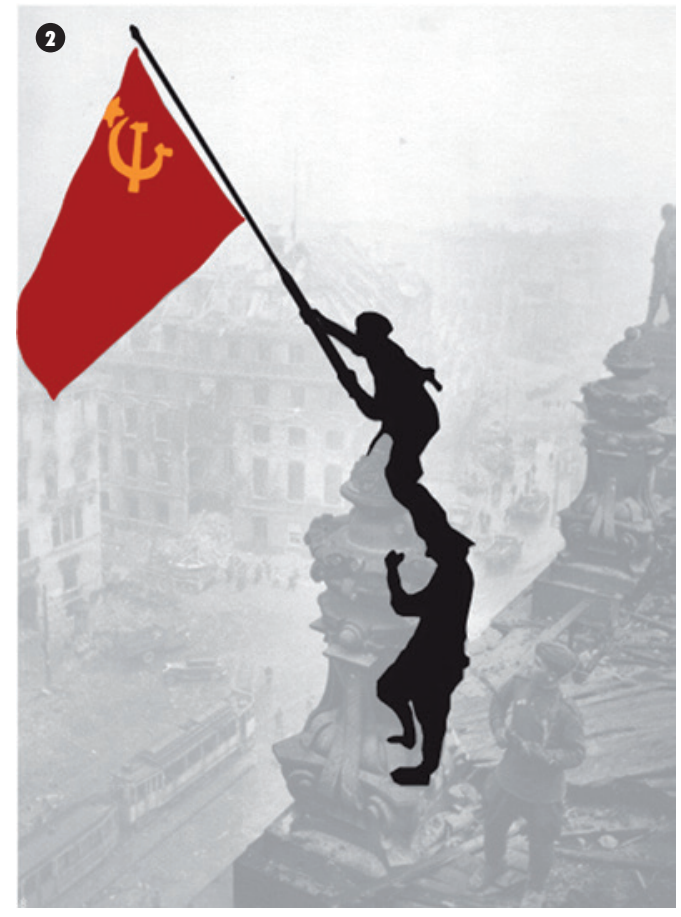

de la historia en los distintos tipos de ciudades que fueron construidas representando diversas ideas de poder como Atenas, Roma o Brasilia, las cuales generaron el disenso y conflicto con sus habitantes. Estos últimos reaccionaron y construyeron sus respuestas agonistas mediante sobrepuestos arquitectónicos.

Retomemos el ejemplo respecto de la toma del Reichstag por parte del Ejército Rojo en el fin de la Segunda Guerra Mundial. La famosa fotografía de Yevgueni Jaldéi muestra cómo un soldado ruso alza la bandera de la Unión Soviética sobre el emblemático edificio, con Berlín arrasado como telón de fondo. Vemos aquí a la arquitectura, representada por el Reichstag, como el símbolo de una ideología provocadora. La respuesta a ello es la sobreposición de la bandera roja sobre su tejado. ¿̇Por qué ahí? ¿̇Por qué en el Reichstag y no en cualquier otro edificio? ¿̇Por qué la bandera y no cualquier otro objeto? La respuesta parece evidente, pero sirve precisamente para ejemplificar cómo la ciudad y la arquitectura son, en sus distintos niveles causantes, provocadores y consecuencia del conflicto. Podemos hablar incluso de un ejemplo inverso y más cercano a nuestra realidad, como fue la ocupación del edificio de la ex UNCTAD III por la Junta Militar de Gobierno y su transformación en el Edificio Diego Portales luego del Golpe de Estado de 1973. En este caso, un edificio que representaba una idea del poder obrero y de la construcción de un país socialista en democracia fue despojado de los sobrepuestos artísticos y políticos que tenía para convertirse en un edificio vacío, cerrado y ajeno a la población, representando ahora una nueva idea y la dureza de la dictadura militar chilena.

\section{SANTIAGO AGONISTA}

El conflicto nace de las estructuras urbanas, pues es en la ciudad, la polis, donde la política y lo político se nutren en base a la confrontación de ideas. Detrás de toda idea política hay un telón de fondo arquitectónico o urbano desde el cual se comunica, pasando desde fachadas y balcones hasta la calle misma. Ejemplo de ello es cómo la arquitectura moderna intentó moldear la sociedad mediante una agencia o inteligencia definida por un mundo de orden y progreso racional que manifestaba a través de la arquitectura símbolos de poder y orden. Desde las viviendas diseñadas racionalmente para ser una máquina de habitar hasta la torre y los complejos representantes del Estado, la autoridad, la economía, entre otros, la modernidad trajo consigo una agencia que generó una respuesta agonista de los habitantes al conflicto entre la inteligencia impuesta versus la local. La modernidad ha sido el foco de confrontación de esos símbolos y los habitantes, quienes interviniendo las edificaciones mediante sobrepuestos, generalmente políticos, los convierten en un espacio propicio para la acción agonista. Santiago es un fiel representante de esta situación.

Nuestra capital ha sido, y es actualmente, un foco permanente de diferentes conflictos, desde problemas económicos, de justicia y de derechos hasta problemas morales, éticos y de convivencia. Podríamos afirmar que Santiago se funda en base al conflicto, con una Plaza de Armas como el espacio de confrontación y una estructura urbana que segregaba según poder económico y político. A lo largo de su crecimiento, muchos de los espacios de Santiago han sido utilizados como dispositivos políticos, siendo uno de los más recurrentes la calle y el espacio público. A través de sobrepuestos arquitectónicos se han construido entornos visuales que cambiaron aquello definido por una estructura elemental en algo de significancia política y agonista, tales como la "Casa de Vidrio" (1999), la toma del encauce del Río Mapocho (2009), "Ad Augusta per Angusta" (2014), "Soy Autopista" (2008), la bandera por la educación sobre la Torre 15 (2011) y los papelógrafos de la "Brigada Chacón en Santa Lucía" (presente). Estos reafirman que la arquitectura no es un actor pasivo dentro de lo social, sino que es un agente activo a través de la discusión de temas conflictivos dentro de los espacios urbanos. Por ello no debería sorprender su uso en la confrontación de ideas políticas contra agencias establecidas en la sociedad y su reflejo en la ciudad a través de conflictos de poder entre la arquitectura representativa del poder institucional y las personas. En efecto, el concepto de poder es la agencia principal en los casos mencionados, lo que demuestra un objetivo principal en la sobreposición de elementos y del conflicto agonista: enfrentar las grandes estructuras en su mismo espacio, jugando en su misma cancha pero con una estrategia distinta

Santiago es un espacio de disenso, sobre todo en su centro, donde se concentran las instituciones que gobiernan el país. Es un escenario de confrontaciones permanentes entre quienes ostentan el poder y los habitantes que los cuestionan. Aquí la arquitectura tiene un papel importante. No es una herramienta pasiva, pues ella modifica y da cualidades diversas a lo que consideramos nuestro ambiente natural y según sus decisiones y construcciones provocará acciones diversas en quienes la rodean y comienzan a adaptarla. Si la arquitectura tiene la capacidad de ser un agente 
más, capaz de impulsar cambios y representar ideas, entonces los sobrepuestos arquitectónicos son también parte de ella, pues son todo aquello que la arquitectura misma provoca a nivel de decisiones y reacciones. Los sobrepuestos arquitectónicos no aparecen espontáneamente sino que a través de procesos de diseño tan complejos como los de la arquitectura misma, los que buscan en el mismo espacio enfrentarse al poder con medios diferentes. Papelógrafos, carteles, combis con cenizas, banderas, carpas, lienzos entre otros son también parte de la arquitectura y de lo social, como elementos que reaccionan a lo construido y provocan reacción. Aceptar estos sobrepuestos dentro de nuestros límites de acción no es eludir el marco disciplinar, sino que es entenderlo como uno más complejo en que los edificios para ser relevantes hoy deben contener estas tecnologías políticamente activas (Jaque, 2014).

Como arquitectos debemos internalizar el papel que juega lo que diseñamos en nuestras ciudades y el poder que tiene para generar cambios y provocar reacciones no controladas ni previstas por nosotros. Su comprensión, y no su rechazo, nos permitirían una mejor construcción de nuestro entorno. No nos deberíamos indignar si a nuestros proyectos les pintan un mural o si a una casa le aparece una expansión, por el contrario, deberíamos entender las razones. No debemos considerar que la arquitectura es estática una vez proyectada y materializada, sino que debemos entender que cambia luego de procesos de acciones y reacciones por parte de quienes la habiten. Ese es el poder que tiene la arquitectura en todos sus ámbitos, desde los elementos formales de fundamentals hasta los comunes de sus habitantes.

\section{REFERENCIAS BIBLIOGRÁFICAS}

Alvar, M. (1996). Manual de dialectología hispánica. Barcelona: Ariel.

Jaque, A. (2013). Phantom, Mies as a rendered society. Barcelona: Fundació Mies Van der Rohe.
Jaque, A. (2014). Urban Enactments, Paisajes en contraste. En Arquine, Paisajes en Constraste. Congreso organizado por Arquine, Santiago de Chile.

Jecks, C. (1977). El lenguaje de la arquitectura posmoderna. Barcelona: Gustavo Gili.

Koolhaas, R. (2013). Fundamentals: Rem Koolhaas presenta su Biennale. Recuperado de www. domusweb.it

Koolhaas, R. (2014). Fundamentals. Venecia: Marsilio.

Latour, B. (2005). Reensamblar lo social: una introducción a la teoría del actor-red. Buenos Aires: Manantial.

Mouffe, C. (2007). En torno a lo político. Buenos Aires: Fondo de la Cultura Económica.

Simonetti-Grez, S. (2014). Santiago como escenario de confrontaciones agenciadas: Manifestaciones agonistas a través del sobrepuesto arquitectónico (Seminario de investigación). Universidad de Chile, Santiago.

Walker, E. (2010). Lo ordinario. Barcelona: Gustavo Gili. 